\title{
Spectrum of Benign Histopathological Lesions in Cholecystectomy Specimens
}

\author{
Prachi Singh ${ }^{\oplus 1}$, Faiyaz Ahmad ${ }^{\circledR 2}$, Shyamoli Dutta ${ }^{\oplus 2}$, Seema Awasthi ${ }^{\odot 3}$, V. K Singh ${ }^{\odot} 4$ \\ ${ }^{1}$ Post Graduate Student, Department of Pathology, Teerthanker Mahaveer Medical College \& Research Centre, TMU, Moradabad, Uttar Pradesh, India, ${ }^{2}$ Professor, \\ Department of Pathology, Teerthanker Mahaveer Medical College \& Research Centre, TMU, Moradabad, Uttar Pradesh, India, ${ }^{3}$ Professor and Head, Department of \\ Pathology, Teerthanker Mahaveer Medical College \& Research Centre, TMU, Moradabad, Uttar Pradesh, India, 4Professor and Head, Department of Internal Medicine, \\ Teerthanker Mahaveer Medical College \& Research Centre, TMU, Moradabad, Uttar Pradesh, India.
}

\section{Abstract}

Background: The most commonly received specimen in any histopathology laboratory is cholecystectomy specimen. The majority of the cholecystectomies are done for Cholelithiasis. Inflammation may be acute, chronic or acute on chronic. It almost always occurs in association with gallstones, which is responsible for carcinoma and if the diagnosed early prognosis of the carcinoma gall bladder is good. Histopathological examination is therefore a must for diagnosis of early carcinomas. Subjects and Methods: 100 cholecystectomy specimens from patients of all ages were included. All specimens were subjected to gross and microscopic assessment. Different histological findings were noted in various layers of the gall bladder. The study includes all radiologically confirmed inflammatory pathologies of including metaplastic changes of the gall bladder epithelium, irrespective of age and sex. The study excludes patients with evident gallbladder malignancy, cases with known secondaries from gall bladder, traumatic rupture of gallbladder. Results: The age of patients varied from 16 to 70 years, with a maximum number of patients (25\%) belong to 31 to 40 years. Gall stones were associated with 59\% cases of cholecystitis. Pigment stones were most common (74\%). Histopathologically the most common diagnosis was chronic cholecystitis (69\%). Conclusion: Almost all of the gallbladder lesions are inflammatory in origin, of which the most common disease being chronic cholecystitis. Chronic cholecystitis was found to be most probable diagnosis in a female of 30-40 years. Pigmented gall stones were found to be the most common etiology of chronic cholecystitis. Prompt detailed histopathological analysis will help to confirm the benign nature of the disease or to detect any precursors of malignancy.

Keywords: Cholecystitis, Cholelithiasis, Histopathological Lesions

Corresponding Author: Faiyaz Ahmad, Professor, Department of Pathology, Teerthanker Mahaveer Medical College \& Research Centre, TMU, Moradabad, Uttar Pradesh, India.

E-mail: dr.faiyaz146@gmail.com

Received: 2 April 2020

Revised: 11 June 2020

Accepted: 19 June 2020

Published: 6 July 2020

\section{Introduction}

The gall bladder is a saccular organ, situated underlying liver, diseases affecting gall bladder constitute a major chunk amongst all commonly occurring diseases worldwide. ${ }^{[1,2]}$ The occurrence of calculous associated gall bladder diseases in India is $2-29 \%{ }^{[3]}$

The most commonly received specimen in any histopathology laboratory is cholecystectomy specimen. Usually, chronic inflammation of gall bladder mucosa i.e.chronic cholecystitis is the most common finding, in the benign histopathological spectrum, in addition, other lesions are acute inflammation, cholesterol is, metaplasia and hyperplasia are observed. Gallbladder carcinoma is a rare malignancy with overall poor prognosis especially if diagnosed late. That is why the histopathological examination of every cholecystectomy specimen is of crucial importance. ${ }^{[4]}$

Cholecystectomy is the most commonly performed surgical intervention for gall bladder diseases. The majority of the cholecystectomies are performed for cholelithiasis. Inflammation of gall bladder may be acute, chronic or acute superimposed on chronic. It almost always occurs in association with gall stones. ${ }^{[5]}$

Risk-factors associated with gall bladder diseases are classified as modifiable like sedentary lifestyle, obesity, metabolic syndrome, pregnancy and parity, high fat \& low fiber diet. Non-modifiable factors include age, sex, hereditary and ethnicity. Mostly (80\%) gall bladder stones are asymptomatic but at times numerous complications are associated with cholecys- 
titis and can lead to significant morbidity and mortality. ${ }^{[1]}$

Benign histopathological spectrum of gall bladder lesions includes acute on chronic cholecystitis, chronic calculous cholecystitis, gangrenous cholecystitis, eosinophilic cholecystitis, xanthogranulomatous cholecystitis, cholesterol polyp, cholesterolosis, empyema, choledochal cyst, metaplasia and focal mucosal hyperplasia. Neoplastic conditions include inflammatory pseudotumor, adenocarcinoma and neuroendocrine carcinoma.

Gall stone associated cholecystitis is common infertile females in their forties, although males and children can also be affected. This disease has increased in the past 20 years due to increase intake of unhealthy food containing fat, lack of physical activity, increased body mass index and sedentary lifestyle. ${ }^{[6]}$

Gallstones cause chronic inflammation which is responsible for gall bladder carcinoma. The frequency of occurrence of carcinoma gallbladder associated with gallstones varies from 0.3 to 12 percent. Histopathological examination is therefore must for diagnosis of early carcinomas. If diagnosed early in stage I then prognosis of carcinoma gall bladder is good. ${ }^{[7]}$

\section{Subjects and Methods}

The study was a retrospective study conducted in the Department of Pathology, TMMC \& RC, Moradabad during the period of one year between May 2018 and May 2019. Total 100 cholecystectomy specimens belonging to patients of all ages were included in the study. Clinical details and relevant clinical findings were recorded. The consent from the patients was taken in the clinical surgical department before the surgical procedure.

After surgery specimens were received in the histopathology in $10 \%$ buffered formalin and processed. All specimens were subjected to detailed gross and microscopic assessment. Sections were given and submitted for processing by paraffin embedding. An appropriate number of 4-5 micron thick tissue sections were cut and stained routinely with Hematoxylin and Eosin $(\mathrm{H} \& \mathrm{E})$. Different histological findings were noted in various layers of gall bladder. Data regarding various etiologies of gallbladder lesions were collected and analyzed using statistical tools

\section{Inclusion criteria}

All the radiologically confirmed cases of inflammatory pathologies of gall bladder including metaplastic changes of the gall bladder epithelium, irrespective of age and sex were included.

\section{Exclusion criteria}

Patients with evident gallbladder malignancy, on clinical grounds and confirmed radiologically were excluded.
Gallbladders showing gross abnormalities suggestive of localized or infiltrative malignancy were excluded from the study.

All the cases of histopathologically confirmed malignant gallbladder lesions were excluded from this study. All cases with known secondaries from the gallbladder, local invasion from other viscera, traumatic rupture of the gallbladder, gross malignancy of gallbladder found during surgery were excluded from the study.

\section{Results}

Total of 100 cholecystectomy specimens included as per criteria during (May 2018 to May 2019) was assessed grossly $\&$ histopathologically. Gallstones and associated diseases were found to be more common in women with a sex incidence ratio of $1: 4.5$.

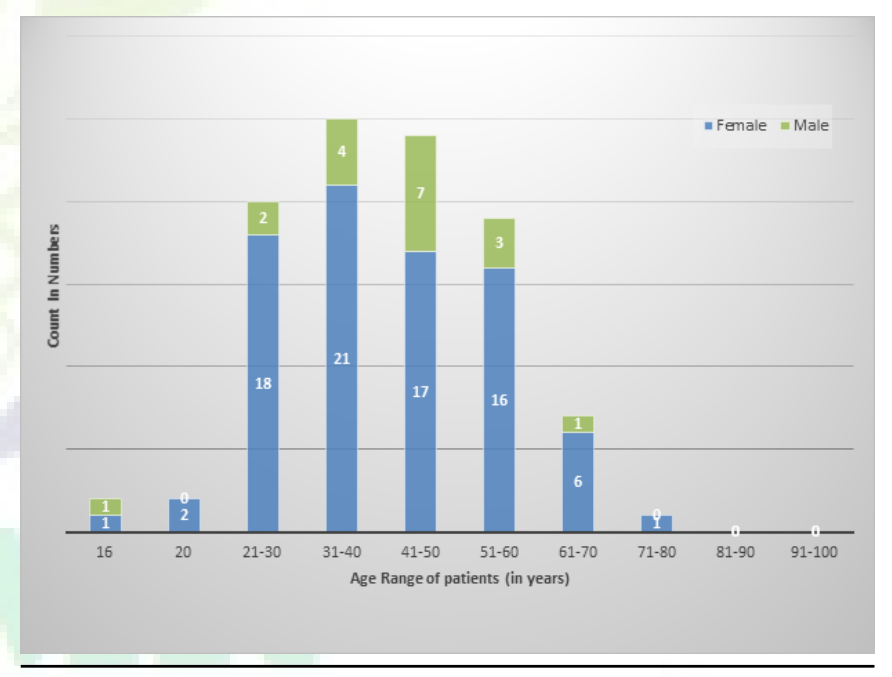

Diagram 1: Age and gender distribution of cases

Types of cholecystitis based on association with gall stones [Chart 1].

The age of patients varied from 16 to 70 years, with a maximum number of patients $(25 \%)$ belong to 31 to 40 years.

Gall stones were associated with $59 \%$ cases of cholecystitis, and significantly associated with various lesions. Pigment stones were most common (74\%) among all types, followed by cholesterol (16\%) and mixed (10\%) stones.

Histopathologically the most common diagnosis was chronic cholecystitis $(69 \%)$, followed by chronic cholecystitis with atypia (9\%), and xanthogranulomatous cholecystitis with $(6 \%)$ cases. There were 4 cases of acute on chronic cholecystitis, 4 cases of eosinophilic cholecystitis, 2 cases of follicular cholecystitis, 1 case each of lymphoplasmacytic and gangrenous cholecystitis. 


\begin{tabular}{|l|llll}
\hline \multicolumn{2}{l}{ Table 1: Gender distribution in the specific age group range } & & \\
\hline Age Range of patient (yrs) & Female & Male & Frequency & Percentage \\
\hline $1-10$ & 0 & 0 & 0 & 0 \\
$11-20$ & 3 & 1 & 4 & 4 \\
$21-30$ & 18 & 2 & 20 & 20 \\
\hline $1-40$ & 21 & 4 & 25 & 25 \\
$41-50$ & 17 & 7 & 24 & 24 \\
\hline $51-60$ & 16 & 3 & 19 & 19 \\
$61-70$ & 6 & 1 & 7 & 7 \\
$71-80$ & 1 & 0 & 1 & 1 \\
$81-90$ & 0 & 0 & 0 & 0 \\
$91-100$ & 0 & 0 & 0 & 0 \\
\hline Total & & & $\mathrm{N}=100$ & \\
\hline
\end{tabular}

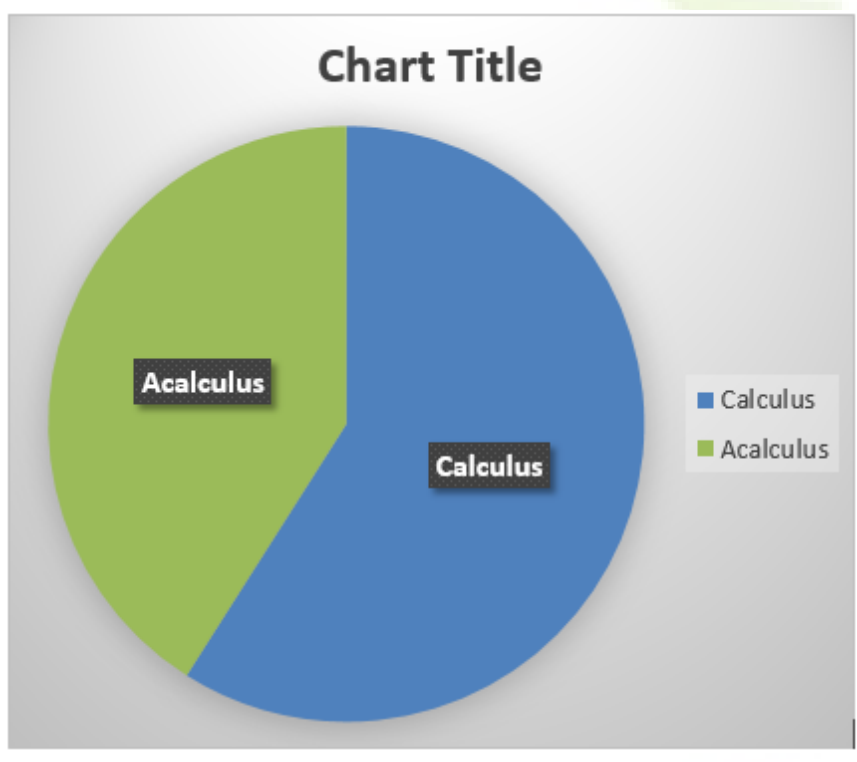

Chart 1: Distribution of calculus and acalculous cholecystitis

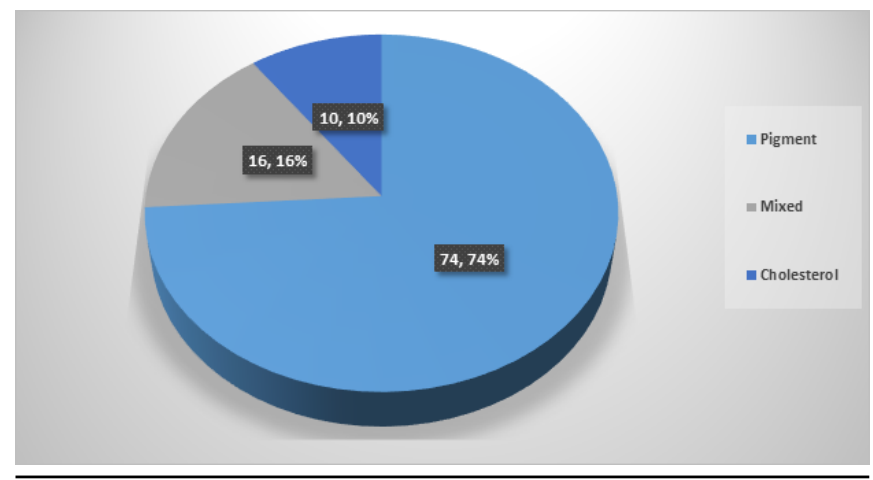

Chart 2: Distribution of gallstones based on morphology
- Mean age of presentation-42.53 yrs.

- Female:Male ratio=(4.5:1).

- The highest number of patients were observed in age group(31-40) years.

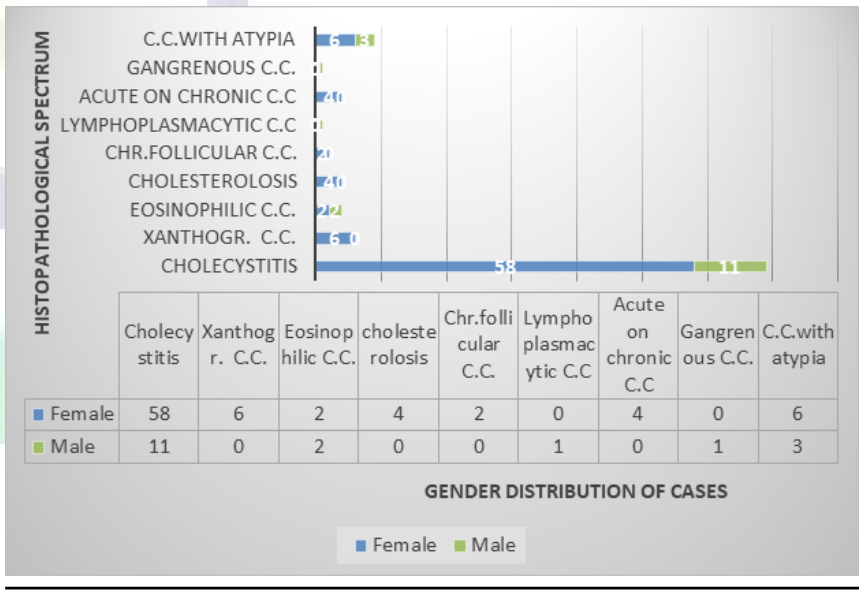

Diagram 2: Gender distribution of histopathological lesions in cholecystectomy specimens

\section{Discussion}

holecystitis is a broad category of disorders used to describe all inflammatory gall bladder conditions irrespective of their different etiopathogenesis and clinical features. Among all cases, a total of $59 \%$ of the chronic cholecystitis cases were found to be associated with gall stones. Chronic acalculous cholecystitis was less commonly found in the present study.

In the present retrospective study of 100 cases, there were 18 men and82 women with a M: F ratio of1:4.5, which was consistent withkhan et al, and Ghimire et al. ${ }^{[4,10]}$ 


\begin{tabular}{|c|c|c|c|c|c|c|}
\hline $\begin{array}{l}\text { Age } \\
\text { (years) }\end{array}$ & Group & Present Study & $\operatorname{Arathi}^{[8]}(2013)$ & $\begin{array}{l}\text { Ozgur et } \text { al }^{[9]} \\
(2013)\end{array}$ & $\begin{array}{l}\text { Ghimire } \\
\text { al }^{[10]}(2012)\end{array}$ & $\begin{array}{l}\text { Narendra et } \text { al }^{[11]} \\
(2015)\end{array}$ \\
\hline $11-20$ & & $4.0 \%$ & $2.9 \%$ & $0.0 \%$ & $0.0 \%$ & $10 \%$ \\
\hline $21-30$ & & $20 \%$ & $18.2 \%$ & $13.8 \%$ & $9.6 \%$ & $22 \%$ \\
\hline $31-40$ & & $25 \%$ & $23.5 \%$ & $31.9 \%$ & $20.38 \%$ & $37 \%$ \\
\hline $41-50$ & & $24 \%$ & $27.2 \%$ & $31.9 \%$ & $41.92 \%$ & $15 \%$ \\
\hline $51-60$ & & $19 \%$ & $19.5 \%$ & $20.5 \%$ & $18.46 \%$ & $8 \%$ \\
\hline$>60$ & & $08 \%$ & $8.7 \%$ & $1.7 \%$ & $9.61 \%$ & $8 \%$ \\
\hline
\end{tabular}

Table 3: Comparison between different studies quoted with present study

\begin{tabular}{|c|c|c|c|c|c|}
\hline Studies & Year & place & Sample Size & Male:Female Ratio & $\begin{array}{l}\text { Mean } \\
\text { (yrs) }\end{array}$ \\
\hline Inui ${ }^{[7]}$ et al & 2011 & Pakistan & 220 & $1: 7$ & $32.3+/-5.3$ \\
\hline Arathi ${ }^{[8]}$ et al & 2013 & India & 237 & $1: 6.9$ & 44.2 \\
\hline $\mathrm{Khan}^{[4]}$ et al & 2013 & India & 360 & $1: 4.7$ & 37.2 \\
\hline Ozgur ${ }^{[9]}$ et al & 2013 & Turkey & 432 & $1: 2.4$ & $47.9+/-14.6$ \\
\hline Ghimire $^{[10]}$ et al & 2012 & Nepal & 783 & $1: 4.3$ & - \\
\hline Bawahab ${ }^{[12]}$ et al & 2013 & Bahrain & 803 & $1: 3$ & $41.3 \pm 14.7$ \\
\hline Present Study & 2018-19 & India & 100 & $1: 4.5$ & 42.53 \\
\hline
\end{tabular}

Table 4: Histopathological spectrum of benign gall bladder lesions

\begin{tabular}{lllll}
\hline Type of lesion & Total no. of cases & Female & Male & \% \\
\hline $\begin{array}{l}\text { Chronic cholecystitis } \\
\text { Xanthogranulomatous } \\
\text { cholecystitis }\end{array}$ & 69 & 58 & 11 & 69 \\
\hline $\begin{array}{l}\text { Eosinophilic cholecys- } \\
\text { titis }\end{array}$ & 4 & 6 & 0 & 4 \\
\hline $\begin{array}{l}\text { Cholesterolosis } \\
\begin{array}{l}\text { Chronic follicular } \\
\text { cholecystitis }\end{array}\end{array}$ & 2 & 2 & 2 & 4 \\
\hline $\begin{array}{l}\text { Lymphoplasmacytic } \\
\text { cholecystitis }\end{array}$ & 1 & 4 & 0 & 2 \\
\hline $\begin{array}{l}\text { Acute on chronic } \\
\text { cholecystitis }\end{array}$ & 4 & 2 & 0 & 1 \\
\hline $\begin{array}{l}\text { Gangrenous cholecys- } \\
\text { titis }\end{array}$ & 1 & 0 & 1 & 4 \\
\hline $\begin{array}{l}\text { Cholecystitis with } \\
\text { atypia }\end{array}$ & 9 & 4 & 0 & 1 \\
\hline
\end{tabular}




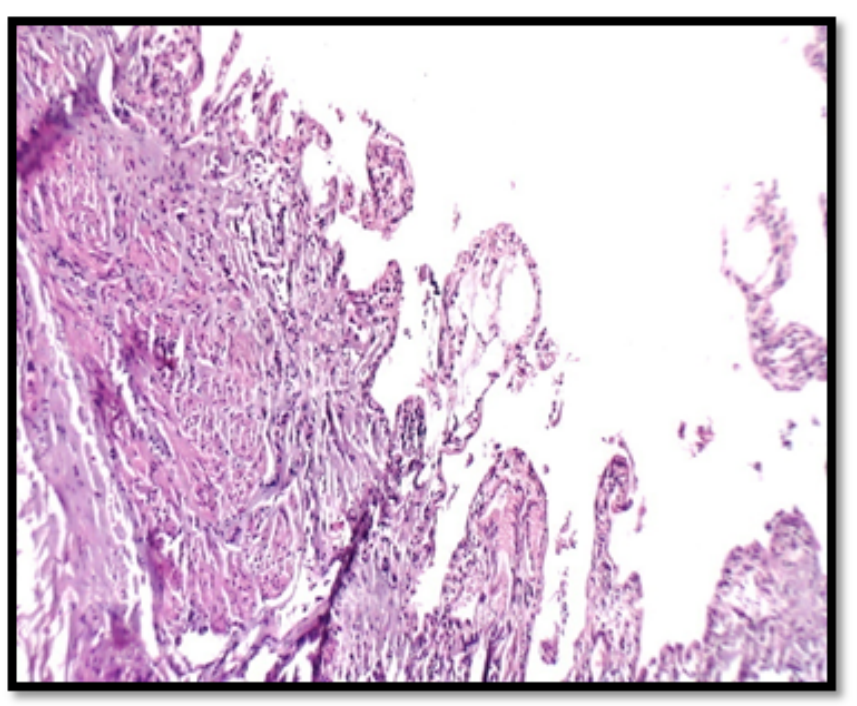

Figure 1: 1: Photomicrograph showing Cholesterolosis

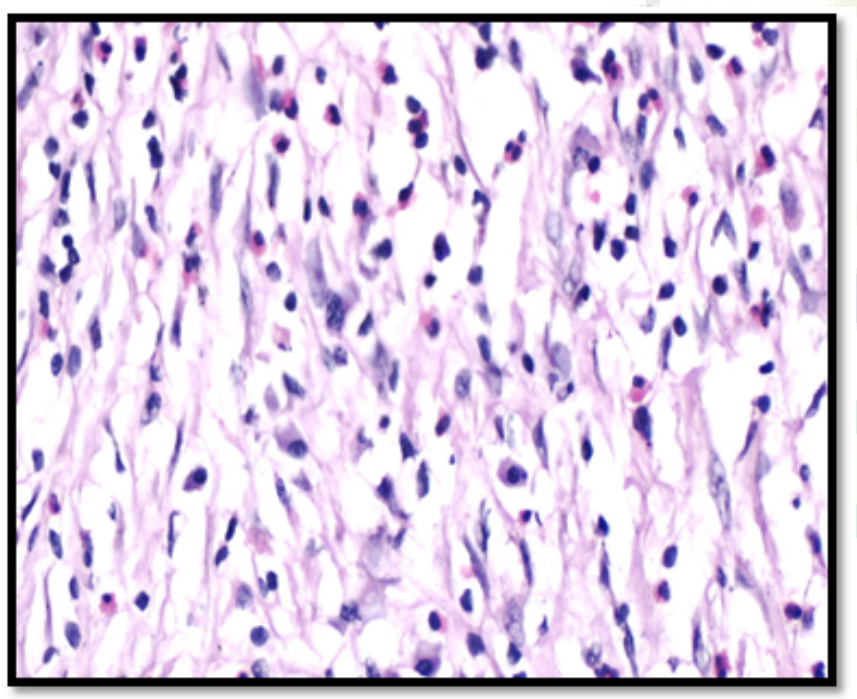

Figure 2: Photomicrograph - Eosinophilic cholecystitis

Most of the patients complained of pain in abdomen (80\%), followed by dyspepsia and vomiting. None of the patients has presented with any evidence of malignancy clinically. This finding was similar to studies done by Narendra et al., Naqvi et al., and Siddhiqui et al. ${ }^{[7,11,13]}$

Worldwide Gallstones are a major cause of mortality and morbidity.

Pigmented stones were more predominant 74(74\%) followed by cholesterol stones in $16(16 \%)$ cases and mixed stones in $10(10 \%)$ cases, which was similar to the study conducted by

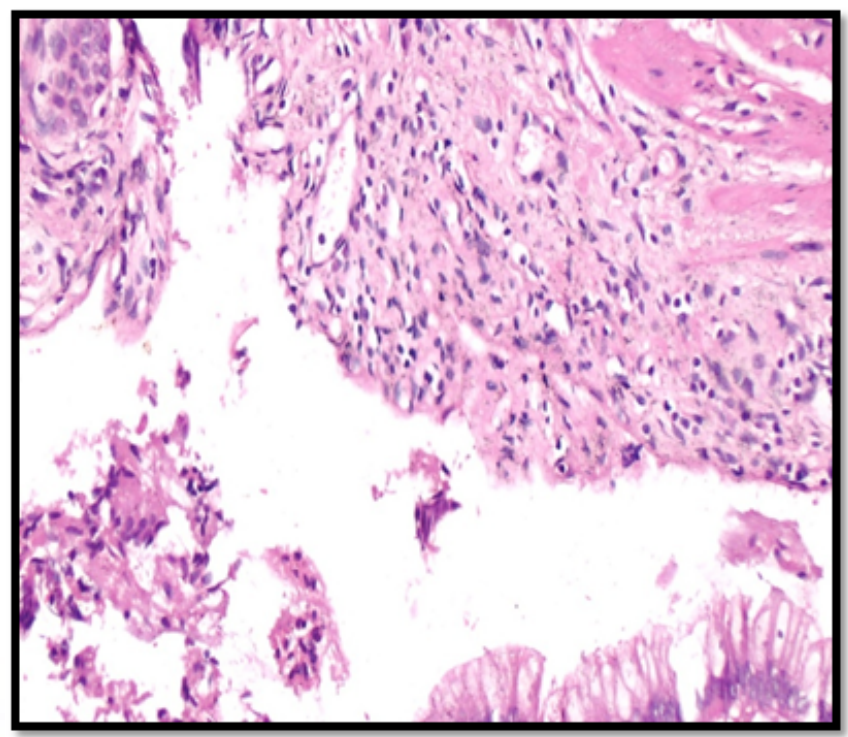

Figure 3: Photomicrograph-Chronic cholecystitis with mucosal hyperplasia with focal atypia

Selvi et al who evaluated 78 cholecystectomy specimens out of which 65 cases $(83.3 \%)$ had stones and 13 cases $(16.6 \%)$ was presented with no calculi and majority were pigmented stones $(60.2 \%) .{ }^{[14]}$ In contrast, Goyal et al in his study with 346 cholecystectomy specimens, got predominantly mixed stones in 213 cases $(68 \%){ }^{[15]}$

In the present study, all the cases were found to have inflammation, in which the predominant cell population was lymphoplasmacytic type in (72)\%. Eosinophils and neutrophils were predominantly present in $4 \%$ and $5 \%$ cases respectively. 2 cases showed lymphoid aggregates. Epithelial atypia was observed in total $9 \%$ cases. Other histological features observed were foamy histiocytes, multinucleated giant cells, ulceration of mucosa, denudation, fibrosis, RA Sinus, hyperplasia and metaplasia.

\section{Conclusion}

Almost all of the gallbladder lesions are inflammatory in origin, of which the most common disease being chronic cholecystitis. From this study it may also be concluded that chronic cholecystitis is the most probable diagnosis in a female of 30-40 years presenting with abdominal pain. Pigmented gall stones were found to be the most common etiology of chronic cholecystitis. Lastly, malignancy of the gallbladder in this population is a rare occurrence. In addition to the direct conclusions from the study, it must be noted that prompt detailed histopathological analysis of the cholecystectomy specimens will not only help to confirm the benign nature 
of the disease but also enables to detect any precursors of malignancy. This will be decisive in the management and prognosis of the patient. Therefore, care must be taken to ensure adequate and immediate fixation of specimens by the surgeon accompanied by a meticulous macroscopic and microscopic evaluation by the pathologists.

\section{References}

1. Stinton LM, Shaffer EA. Epidemiology of Gallbladder Disease: Cholelithiasis and Cancer. Gut Liver. 2012;6(2):172-187. Available from: https://dx.doi.org/10.5009/gnl.2012.6.2.172.

2. Kafle SU, Sinha AK, Pandey SR. Histomorphology spectrum of gall bladder pathology in cholecystectomy specimens with clinical diagnosis of chronic cholecystitis. J Nepal Med Assoc. 0192;52:600-607.

3. Kumar H, Kini H, Tiwari A. Histological evaluation of 400 cholecystectomy specimens. J Pathol Nepal. 2015;5(10):834840. Available from: https://dx.doi.org/10.3126/jpn.v5i10. 15640.

4. Khan S, Jetley S, Husain M. Spectrum of histopathological lesions in cholecystectomy specimens: A study of 360 cases at a teaching hospital in South Delhi. Arch Int Surg. 2013;3(2):102102. Available from: https://dx.doi.org/10.4103/2278-9596. 122927.

5. Stinton LM, Shaffer EA. Epidemiology of Gallbladder Disease: Cholelithiasis and Cancer. Gut Liver. 2012;6(2):172-167. Available from: https://dx.doi.org/10.5009/gnl.2012.6.2.172.

6. Rosai A. Acute cholecystitis. BMJ. 2002;325(7365):639-643. Available from: https://dx.doi.org/10.1136/bmj.325.7365.639.

7. Inui K, Yoshino J, Miyoshi H. Diagnosis of Gallbladder Tumors. Internal Med. 2011;50(11):1133-1136. Available from: https://dx.doi.org/10.2169/internalmedicine.50.5255.

8. Arathi N, Awasthi S, Kumar A. Pathological profile of cholecystectomies at a tertiary centre. Natl J Med Dent Res. 2013;2(1):28-38.

9. Ozgur T, Toprak S, Koyuncuer A, Guldur M, Bayraktar G, Yaldiz M. Do histopathologic findings improve by increasing the sample size in cholecystectomies? World J Surg Oncol.
2013;11(1):245-245. Available from: https://dx.doi.org/10. 1186/1477-7819-11-245.

10. Ghimire P, Yogi N, Shrestha BB. Incidence of incidental carcinoma gall bladder in cases of routine cholecystectomy. Kathmandu Univ Med J. 2012;9(2):3-6. Available from: https: //dx.doi.org/10.3126/kumj.v9i2.6278.

11. Narendra GN, Gautam K. A spectrum of benign gallbladder diseases and their laparoscopic management: An experience of 100 patients. IJHRMLP. 2015;1(2):25-31.

12. Bawahab MA, Maksoud WME, Amri FSA, Ali HF, Salman ANA. Does Routine Histopathological Examination of Gallbladder after Simple Cholecystectomy Add Additional Value ? Bahrain Med Bull. 2013;35(4):193-195. Available from: https://dx.doi.org/10.12816/0004446.

13. Naqvi S, Mangi IH, Dahri FJ, Khaskheli QA, Akhund AA. Frequency of carcinoma of gallbladder in patients with cholelithiasis. Gomal J Med Sci. 2005;3(2):34-38.

14. Selvi T, Sinha P, Subramaniam PM, Konapur PG, Prabha CV. A clinicopathological study of cholecystitis withspecia 1 reference to analysis of cholelithiasis. Int $\mathrm{J}$ Basic Med Sci. 2011;2(2):68-72.

15. Goyal S, Singla S, Duhan A. Correlation between gallstones characteristics and gallbladder mucosal changes: A retrospective study of 313 patients. Clin Cancer Invest J. 2014;3(2):157157. Available from: https://dx.doi.org/10.4103/2278-0513. 130215 .

Copyright: (C) the author(s), 2020. It is an open-access article distributed under the terms of the Creative Commons Attribution License (CC BY 4.0), which permits authors to retain ownership of the copyright for their content, and allow anyone to download, reuse, reprint, modify, distribute and/or copy the content as long as the original authors and source are cited.

How to cite this article: Singh $\mathrm{P}$, Ahmad F, Dutta S, Awasthi $\mathrm{S}$, Singh VK. Spectrum of Benign Histopathological Lesions in Cholecystectomy Specimens. Asian J. Med. Res. 2020;9(2):8-13.

DOI: dx.doi.org/10.47009/ajmr.2020.9.2.PT2

Source of Support: Nil, Conflict of Interest: None declared. 